\title{
Correction to: Vermiculite-Lizardite Industrial Wastes Promote Plant Growth in a Peat Soil Affected by a Cu/Ni Smelter: a Case Study at the Kola Peninsula, Russia
}

\author{
Ekaterina Tarasova $^{1}$ - Svetlana Drogobuzhskaya ${ }^{2}$ - Felipe Tapia-Pizarro ${ }^{3}$ - Dmitry V. Morev ${ }^{4}$. Vasyl A. Brykov ${ }^{1,5}$. \\ Elvira A. Dovletyarova ${ }^{1}$ - Marina Slukovskaya ${ }^{6}$. Claudia Navarro-Villarroel $^{7}$ - Anna A. Paltseva ${ }^{1,8}$. \\ Alexander Neaman ${ }^{3}$ (iD
}

Published online: 26 May 2020

(C) Sociedad Chilena de la Ciencia del Suelo 2020

\section{Correction to: Journal of Soil Science and Plant Nutrition https://doi.org/10.1007/s42729-020-00188-z}

The Funding Information provided in this article is incomplete. Here is the Funding Information in its entirety:

Funding information This study was supported by the Russian Science Foundation (project 19-77-00077), the Russian Academy of Sciences (research topic № 01862019-0011), the CONICYT PIA/BASAL FB0002 project (Center of Applied Ecology and Sustainability, CAPES), and the RUDN University "5-100" project.

Publisher's Note Springer Nature remains neutral with regard to jurisdictional claims in published maps and institutional affiliations.

The online version of the original article can be found at https://doi.org/ 10.1007/s42729-020-00188-Z

Alexander Neaman

alexander.neaman@ucv.cl

1 Department of Landscape Design and Sustainable Ecosystems, RUDN University, Moscow, Russia

2 Kola Science Centre, Russian Academy of Sciences, I.V. Tananaev, Institute of Chemistry and Technology of Rare Elements and Mineral Raw Materials, Apatity, Russia

3 Escuela de Agronomía, Pontificia Universidad Católica de Valparaíso, Quillota, Chile
Department of Ecology, Russian State Agrarian University, Moscow Timiryazev Agricultural Academy, Moscow, Russia

5 Institute of Botany, National Academy of Sciences of Ukraine, Kiev, Ukraine

6 Laboratory of Nature-Inspired Technologies and Environmental Safety of the Arctic, Kola Science Centre, Russian Academy of Sciences, Apatity, Russia

7 Instituto de Estadística, Universidad de Valparaíso, Valparaíso, Chile

Department of Earth and Environmental Sciences, Brooklyn College of The City University of New York, Brooklyn, NY, USA 